\title{
Influence of the anion on the spectroscopy and scintillation mechanism in pure and $\mathrm{Ce}^{3+}$-doped $\mathrm{K}_{2} \mathrm{La} X_{5}$ and $\mathrm{LaX}_{3}(X=\mathrm{Cl}, \mathrm{Br}, \mathrm{I})$
}

\author{
E. V. D. van Loef, ${ }^{1}$ P. Dorenbos, ${ }^{1}$ C. W. E. van Eijk, ${ }^{1}$ K. W. Krämer, ${ }^{2}$ and H. U. Güdel ${ }^{2}$ \\ ${ }^{1}$ Interfaculty Reactor Institute, Delft University of Technology, Mekelweg 15, $2629 \mathrm{JB}$ Delft, The Netherlands \\ ${ }^{2}$ Department of Chemistry and Biochemistry, University of Bern, Freiestrasse 3, 3000 Bern 9, Switzerland
}

(Received 14 March 2003; published 11 July 2003)

\begin{abstract}
The optical properties and scintillation mechanism in pure and $\mathrm{Ce}^{3+}$-doped $\mathrm{K}_{2} \mathrm{La} X_{5}$ and $\mathrm{La} X_{3}$ have been determined under $\mathrm{x}$-ray, $\gamma$-ray, vacuum ultraviolet light, and synchrotron radiation excitation. Special attention is paid to the influence of anions $X=\mathrm{Cl}^{-}, \mathrm{Br}^{-}$, and $\mathrm{I}^{-}$, and a comparison is made with properties of pure and $\mathrm{Eu}^{2+}$-doped $\mathrm{K} X$ compounds. The energies of the $5 d$ excited states of $\mathrm{Ce}^{3+}$ have been determined, and the total crystal field splitting and the centroid shift are discussed. An excitation across the band gap creates a combination of self-trapped exciton (STE) and $\mathrm{Ce}^{3+}$ emission. These emissions are often anticorrelated when temperature or $\mathrm{Ce}^{3+}$ concentration is changed. Their ratio is related to the STE mobility and STE creation rate. Clear trends in the optical properties and scintillation mechanism are observed along the halide series.
\end{abstract}

DOI: 10.1103/PhysRevB.68.045108

\section{INTRODUCTION}

Industrial and technical applications have motivated the research and development of new inorganic scintillators for years. Attention has been given to $\mathrm{Ce}^{3+}$-doped materials, the characterization of their optical and scintillation properties, and the elucidation of the scintillation mechanism. ${ }^{1-4}$

Recently, it was shown that especially the lanthanum halides $\mathrm{LaCl}_{3}$ and $\mathrm{LaBr}_{3}$ doped with $\mathrm{Ce}^{3+}$ have excellent scintillation properties. ${ }^{5,6}$ Both have a high light yield, good energy resolution, and a fast scintillation decay under $\gamma$-ray excitation. A scintillation mechanism involving the role of self-trapped excitons in the energy transfer from the host to $\mathrm{Ce}^{3+}$ was proposed for $\mathrm{LaCl}_{3}: \mathrm{Ce}^{3+}$, recently.

In an attempt to further investigate the influence of the chemical environment on the optical properties and scintillation mechanism of metal-halide scintillators, we decided to work on pure and $\mathrm{Ce}^{3+}$-doped $\mathrm{K}_{2} \mathrm{LaX}_{5}(X=\mathrm{Cl}, \mathrm{Br}$, I). These systems are isostructural, whereas the environment of the $\mathrm{M}^{3+}$ cation is altered by chemical variation of the halide anions from $\mathrm{Cl}$ to $\mathrm{Br}$ to $\mathrm{I}$.

It is well known that the physical and chemical properties of the halogens and their anions change considerably along the series from $\mathrm{F}$ to $\mathrm{Cl}$ to $\mathrm{Br}$ to $\mathrm{I}$. The anion has a profound influence on both the energy of the $5 d$ levels of $\mathrm{Ce}^{3+},{ }^{8-10}$ and the luminescence properties of the pure compound. For instance, the emission energies and lifetimes of self-trapped excitons (STEs) in alkali halides strongly depend on the anion. ${ }^{11}$ Also the dynamic properties of the STE change because, e.g., the energy barrier for STE migration through the lattice decreases from $\mathrm{Cl}$ to $\mathrm{Br}$ to $\mathrm{I}$.

This work reports on the influence of the anion on the optical properties and scintillation mechanism of pure and $\mathrm{Ce}^{3+}$-doped $\mathrm{K}_{2} \mathrm{LaX}_{5}$ with $X=\mathrm{Cl}, \mathrm{Br}$, and I. Both static and dynamic aspects are discussed. The spectroscopic properties of $\mathrm{K}_{2} \mathrm{LaX}_{5}: \mathrm{Ce}^{3+}$ are compared to those of $\mathrm{Ce}^{3+}$ In $\mathrm{LaCl}_{3}$, $\mathrm{LaBr}_{3}$, and to lesser extent $\mathrm{LaI}_{3}$, as well as of $\mathrm{Eu}^{2+}$ in the potassium halides $\mathrm{K} X$. The emission wavelength and lifetime of the STE, the energy of the $4 f 5 d$ states of $\mathrm{Ce}^{3+}$, as well as energy transfer from the STE to $\mathrm{Ce}^{3+}$ are described and discussed.
PACS number(s): 78.55.Hx

\section{EXPERIMENT}

\section{A. Synthesis and structure}

Single crystals of pure and $\mathrm{Ce}^{3+}$-doped $\mathrm{K}_{2} \mathrm{LaX}_{5}(X$ $=\mathrm{Cl}, \mathrm{Br}, \mathrm{I}$ ) were grown by the vertical Bridgman technique using a static ampoule and a moving furnace. We used as starting materials $\mathrm{K} X$ (Merck, suprapur), $\mathrm{La} X_{3}$, and $\mathrm{Ce} X_{3}$. $\mathrm{LaCl}_{3}$ and $\mathrm{LaBr}_{3}$ and $\mathrm{CeCl}_{3}$ and $\mathrm{CeBr}_{3}$ were prepared from $\mathrm{La}_{2} \mathrm{O}_{3}$, using the ammonium halide method. ${ }^{12,13} \mathrm{LaI}_{3}$ and $\mathrm{CeI}_{3}$ were synthesized from the elements. ${ }^{14}$ To remove traces of water and oxygen they were purified by sublimation in tantalum or silica ampoules. For the crystal growth, stoichiometric amounts of the starting materials were sealed in silica ampoules under vacuum. All material handling was done under strictly dry conditions, e.g., in glove boxes with less than 0.1 ppm $\mathrm{H}_{2} \mathrm{O}$.

The ternary halides $\mathrm{K}_{2} \mathrm{LaX}_{5}$ crystallize in the $\mathrm{K}_{2} \operatorname{Pr} X_{5}$-type structure, space group Pnma (no. 62). ${ }^{15}$ The structure can also be described as a hexagonal densest arrangement of chains of edge-connected polyhedra $\left[\mathrm{LaX}_{7}\right]$. The polyhedra may be viewed as distorted monocapped trigonal prisms with the $\mathrm{La}^{3+}$ ion in the center, see Fig. 1. The point symmetry at the La site is $\mathrm{C}_{s}$. The seven $\mathrm{Cl}^{-}$, $\mathrm{Br}^{-}$, or $\mathrm{I}^{-}$ions are at an average distance of $284 \mathrm{pm}, 299$ $\mathrm{pm}$, and $323 \mathrm{pm}$ from the central $\mathrm{La}^{3+}$ ion, respectively. The

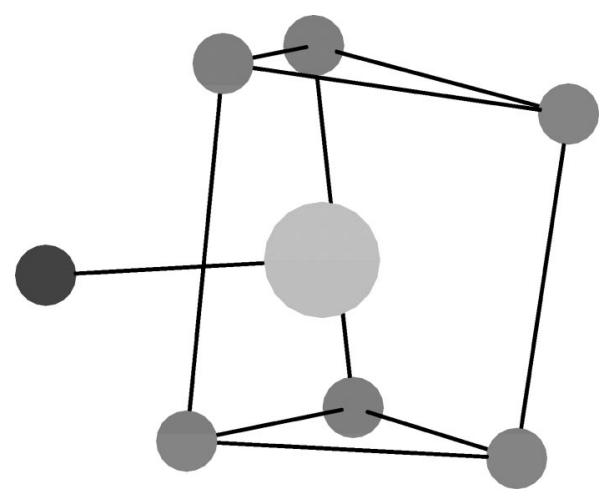

FIG. 1. The distorted monocapped trigonal prism polyhedron around $\mathrm{La}^{3+}$ in $\mathrm{K}_{2} \mathrm{LaCl}_{5}$. 
calculated density of $\mathrm{K}_{2} \mathrm{LaCl}_{5}, \mathrm{~K}_{2} \mathrm{LaBr}_{5}$, and $\mathrm{K}_{2} \mathrm{LaI}_{5}$ is $2.9 \mathrm{~g} / \mathrm{cm}^{3}, 3.9 \mathrm{~g} / \mathrm{cm}^{3}$, and $4.4 \mathrm{~g} / \mathrm{cm}^{3}$, respectively.

\section{B. X-ray excited luminescence spectra}

An x-ray tube with $\mathrm{Cu}$ anode operating at $40 \mathrm{kV}$ and 25 $\mathrm{mA}$ was used to generate $\mathrm{x}$-ray excited luminescence spectra. The spectra were recorded with an ARC VM504 monochromator (blazed at $300 \mathrm{~nm}, 1200$ grooves $/ \mathrm{mm}$ ) and a Hamamatsu R323 photomultiplier tube (PMT). The spectra in this study were corrected for the wavelength dependence of the photodetector quantum efficiency as well as monochromator transmission. The spectral resolution is typically 1 $\mathrm{nm}$. Temperature dependent $\mathrm{x}$-ray excited luminescence measurements were performed between 80 and $400 \mathrm{~K}$, using a Cryospec model 20A Joule-Thomson Miniature Refrigerator operated with $99.999 \%$ nitrogen gas at 120 bar. The temperature was stabilized to within $0.1 \mathrm{~K}$. The actual sample temperature is determined by the thermal coupling of the sample to the cooling device. We estimate an accuracy of about $5 \mathrm{~K}$.

\section{Excitation and emission spectroscopy}

Excitation between 150 and $500 \mathrm{~nm}$ was done by means of an ARC DS-775 deuterium continuous discharge lamp and an ARC VM502 monochromator (blazed at $250 \mathrm{~nm}, 1200$ grooves $/ \mathrm{mm}$ ). The emission spectra were recorded with a Macam 910 UV emission monochromator (blazed at $350 \mathrm{~nm}$, 1200 grooves $/ \mathrm{mm}$ ) and a Philips XP2020Q PMT. The sample holder as well as the excitation monochromator are operated under vacuum. The spectra were corrected for the wavelength dependence of the photodetector quantum efficiency as well as monochromator transmission, using sodium salicylate as a reference.

High-resolution excitation and emission spectra at $10 \mathrm{~K}$ were recorded with synchrotron radiation at the SUPERLUMI station of the Synchrotron Strahlungslabor (HASYLAB) at the Deutsches Elektronen Synchrotron (DESY) in Hamburg (Germany). Details of this facility have been described elsewhere. ${ }^{16}$ The spectral region of excitation was $50-335 \mathrm{~nm}$ with a fixed resolution of $0.3 \mathrm{~nm}$. Luminescence was detected using a cooled Hamamatsu R2059 PMT. The resolution was $1 \mathrm{~nm}$. The synchrotron operated in the multibunch regime (5 bunches) with 192 ns distance between successive bunches. Photons were counted within a time window of $27 \mathrm{~ns}$ at the start of the synchrotron luminescence pulse. Another time window of $106 \mathrm{~ns}$ duration was used at the end of the pulse to discriminate between fast and slow luminescence components. Also the integral count rate was recorded. Excitation spectra were corrected using sodium salicylate as a reference.

\section{Scintillation decay and light yield measurements}

Scintillation decay time spectra at time scales up to $10 \mu \mathrm{s}$ were recorded by the multihit method described by Moses. ${ }^{17}$ The crystals under study were mounted on a Philips XP2020Q "start" PMT. Single photons were detected by another Philips XP2020Q "stop" PMT. Both signals were transformed into fast logic pulses using an Ortec 934 con-
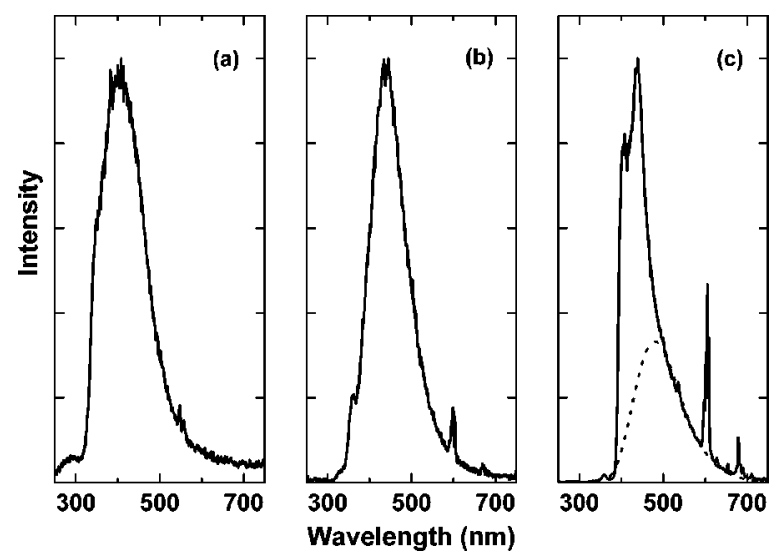

FIG. 2. X-ray excited luminescence spectra of (a) $\mathrm{K}_{2} \mathrm{LaCl}_{5}$, (b) $\mathrm{K}_{2} \mathrm{LaBr}_{5}$, and (c) $\mathrm{K}_{2} \mathrm{LaI}_{5}$ at $80 \mathrm{~K}$. The dotted trace in the spectrum of $\mathrm{K}_{2} \mathrm{LaI}_{5}$ represents the contribution of STEs to the emission.

stant fraction discriminator (CFD). The time differences between the "start" and the "stop" pulses are digitized using a LeCroy 4208 time-to-digital converter (TDC) and stored in a histogram.

The absolute scintillation light yield at room temperature of $\mathrm{K}_{2} \mathrm{LaBr}_{5}: 0.7 \% \mathrm{Ce}^{3+}$ and $\mathrm{K}_{2} \mathrm{LaI}_{5}: 0.7 \% \mathrm{Ce}^{3+}$ was determined from the $662 \mathrm{keV}$ total absorption peak in the pulse height spectrum of a ${ }^{137} \mathrm{Cs}$ source detected with the scintillation crystal mounted on a Hamamatsu R1791 photomultiplier tube. Standard spectroscopic techniques with a shaping time of $10 \mu \mathrm{s}$ and employing the single photoelectron spectrum as reference were used. Further details can be found elsewhere. ${ }^{18,19}$

\section{RESULTS}

\section{A. X-ray excited luminescence}

Figure 2 shows the $\mathrm{x}$-ray excited luminescence spectra of $\mathrm{K}_{2} \mathrm{LaX}_{5}(X=\mathrm{Cl}, \mathrm{Br}, \mathrm{I})$ at $80 \mathrm{~K}$. The spectra are dominated by a broad emission band located between 300 and $550 \mathrm{~nm}$. The emission band can readily be assigned to STE luminescence. For the iodides the emission spectrum of the STE is shown as the dotted trace. The sharp line emissions at 600 and $679 \mathrm{~nm}$ in the iodide spectrum and to a lesser extend in the bromide spectrum are probably due to not further identified rare earth impurities. The sharp decline of intensity in the $\mathrm{K}_{2} \mathrm{LaI}_{5}$ spectrum at wavelengths shorter than $400 \mathrm{~nm}$ is attributed to absorption of STE emission by the $380 \mathrm{~nm} \mathrm{fd}$ transition of $\mathrm{Ce}^{3+}$ present as impurity in the nominally undoped compound. $\mathrm{Ce}^{3+}$ is also the origin for the emission bands observed near 400 and $440 \mathrm{~nm}$. Unintended $\mathrm{Ce}^{3+}$ impurities are also the reason for some structure on the highenergy side of the STE emission in $\mathrm{K}_{2} \mathrm{LaCl}_{5}$ and $\mathrm{K}_{2} \mathrm{LaBr}_{5}$.

$\mathrm{X}$-ray excited luminescence spectra of $\mathrm{K}_{2} \mathrm{LaCl}_{5}: 0.1 \%$ $\mathrm{Ce}^{3+},{ }^{20} \mathrm{~K}_{2} \mathrm{LaBr}_{5}: 0.7 \% \mathrm{Ce}^{3+}$, and $\mathrm{K}_{2} \mathrm{LaI}_{5}: 0.7 \% \mathrm{Ce}^{3+}$ at 80 $\mathrm{K}$ are shown in Fig. 3 (solid traces). Also depicted are the $300 \mathrm{~K}$ spectra of the bromide and the iodide compounds (dotted traces). For all three lattices characteristic $\mathrm{Ce}^{3+} 5 d$ $\rightarrow 4 f$ emission is observed. The maxima are located at 344 and $372 \mathrm{~nm}$ for the chloride, at 359 and $391 \mathrm{~nm}$ for the 


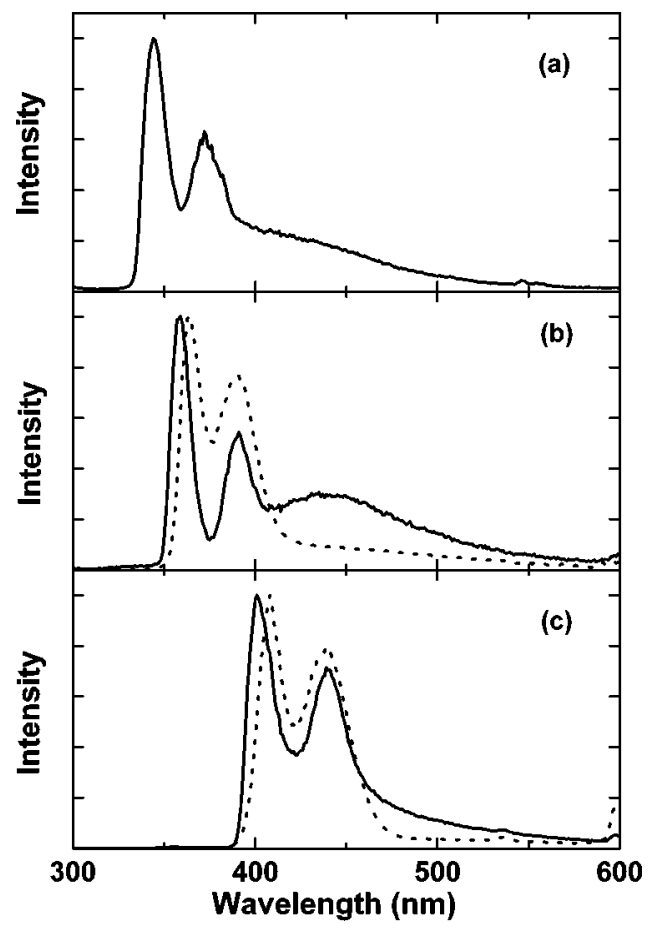

FIG. 3. X-ray excited luminescence spectra of (a) $\mathrm{K}_{2} \mathrm{LaCl}_{5}: 0.1 \% \quad \mathrm{Ce}^{3+}$, (b) $\mathrm{K}_{2} \mathrm{LaBr}_{5}: 0.7 \% \quad \mathrm{Ce}^{3+}$, and (c) $\mathrm{K}_{2} \mathrm{LaI}_{5}: 0.7 \% \mathrm{Ce}^{3+}$. The spectra were measured at $80 \mathrm{~K}$ (solid trace) and at $300 \mathrm{~K}$ (dotted trace).

bromide, and at 401 and $439 \mathrm{~nm}$ for the iodide for the $5 d$ $\rightarrow{ }^{2} \mathrm{~F}_{5 / 2}$ and ${ }^{2} \mathrm{~F}_{7 / 2}$ transitions, respectively. In addition, a weak emission is present as a broadband or tail on the long wavelength side of the $\mathrm{Ce}^{3+}$ doublet. It is attributed to residual STE emission. If the temperature is raised to $300 \mathrm{~K}$, the intensity of this band decreases rapidly and only $\mathrm{Ce}^{3+}$ emission is observed.

The total luminescence intensity under $\mathrm{x}$-ray excitation of $\mathrm{K}_{2} \mathrm{LaBr}_{5}: 0.7 \% \mathrm{Ce}^{3+}$ and $\mathrm{K}_{2} \mathrm{LaI}_{5}: 0.7 \% \mathrm{Ce}^{3+}$ is depicted in Figs. 4 and 5, respectively. From 100 to $175 \mathrm{~K}$, the total luminescence intensity of the bromide and iodide decreases by about $14 \%$ and $22 \%$, respectively. As the temperature rises the $\mathrm{Ce}^{3+}$ luminescence intensity is enhanced at the expense of STE luminescence intensity (compare with Fig. 3). Also the total luminescence intensity increases.

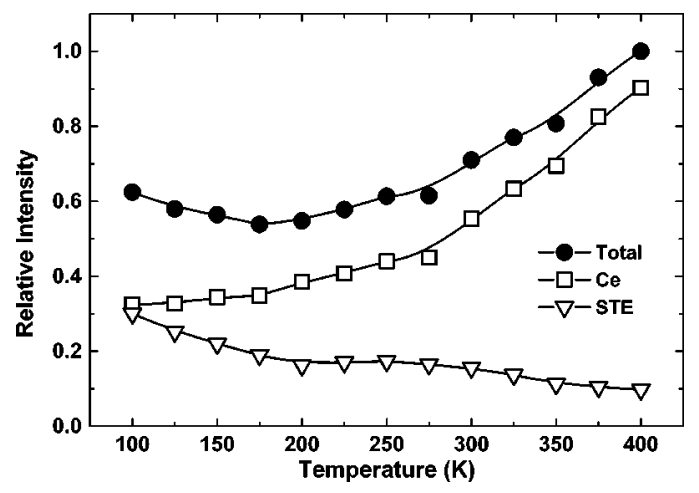

FIG. 4. Temperature dependence of $\mathrm{Ce}^{3+}$, STE, and total luminescence intensity of $\mathrm{x}$-ray excited $\mathrm{K}_{2} \mathrm{LaBr}_{5}: 0.7 \% \mathrm{Ce}^{3+}$.

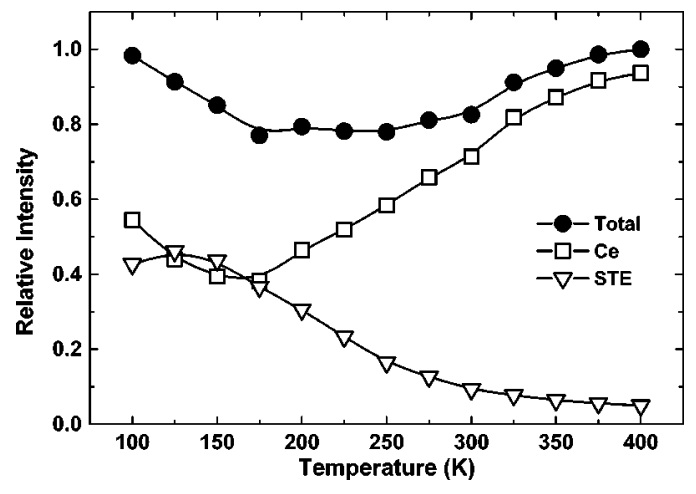

FIG. 5. Temperature dependence of $\mathrm{Ce}^{3+}$, STE, and total luminescence intensity of $x$-ray excited $\mathrm{K}_{2} \mathrm{LaI}_{5}: 0.7 \% \mathrm{Ce}^{3+}$.

This anticorrelation between $\mathrm{Ce}^{3+}$ and STE luminescence has been observed more clearly in $\mathrm{LaCl}_{3}: 0.57 \% \mathrm{Ce}^{3+}$ by Guillot-Noël et al. ${ }^{18}$ and in $\mathrm{K}_{2} \mathrm{LaCl}_{5}: 0.23 \% \mathrm{Ce}^{3+}$ by van't Spijker et al. ${ }^{20}$ It appears to be a general behavior in the $\mathrm{K}_{2} \mathrm{LaX}_{5}$ and $\mathrm{LaX}_{3}$ systems. Furthermore, at $100 \mathrm{~K}$ the ratio of $\mathrm{Ce}^{3+}$ to STE emission increases along the series from $\mathrm{Cl}$ to I. At $100 \mathrm{~K}$ the contributions of $\mathrm{Ce}^{3+}$ and STE luminescence to the total intensity of $\mathrm{K}_{2} \mathrm{LaCl}_{5}: 0.23 \% \mathrm{Ce}^{3+}$ are $15 \%$ and $85 \%$, respectively. ${ }^{18}$ However, for $\mathrm{K}_{2} \mathrm{LaBr}_{5}: 0.7 \% \mathrm{Ce}^{3+}$ and $\mathrm{K}_{2} \mathrm{LaI}_{5}: 0.7 \% \mathrm{Ce}^{3+}$ the contributions of $\mathrm{Ce}^{3+}$ and STE luminescence are almost equal. At $135 \mathrm{~K}$ this is also true for $\mathrm{LaCl}_{3}: 0.57 \% \mathrm{Ce}^{3+},{ }^{19}$ whereas for $\mathrm{LaBr}_{3}: \mathrm{Ce}^{3+}$ the contribution of STE luminescence to the total luminescence intensity is negligible. ${ }^{21}$

The absolute scintillation light outputs determined from $\gamma$ ray pulse height spectra were found to be 21000,26000 , and 52000 photons per $\mathrm{MeV}$ of absorbed $\gamma$ ray energy for $\mathrm{K}_{2} \mathrm{LaCl}_{5}: 0.7 \% \quad \mathrm{Ce}^{3+}, \quad \mathrm{K}_{2} \mathrm{LaBr}_{5}: 0.7 \% \quad \mathrm{Ce}^{3+}$, and $\mathrm{K}_{2} \mathrm{LaI}_{5}: 0.7 \% \mathrm{Ce}^{3+}$, respectively. Measurements were performed at room temperature with a ${ }^{137} \mathrm{Cs}$ source using $10 \mu \mathrm{s}$ shaping time. These numbers demonstrate that the energy transport from the host crystal to $\mathrm{Ce}^{3+}$ is very efficient in this class of materials.

\section{B. Excitation and emission spectroscopy}

Figure 6 compares the excitation spectra of STE emission in pure $\mathrm{K}_{2} \mathrm{LaCl}_{5}$ and $\mathrm{K}_{2} \mathrm{LaBr}_{5}$ at $10 \mathrm{~K}$. We define three dif-

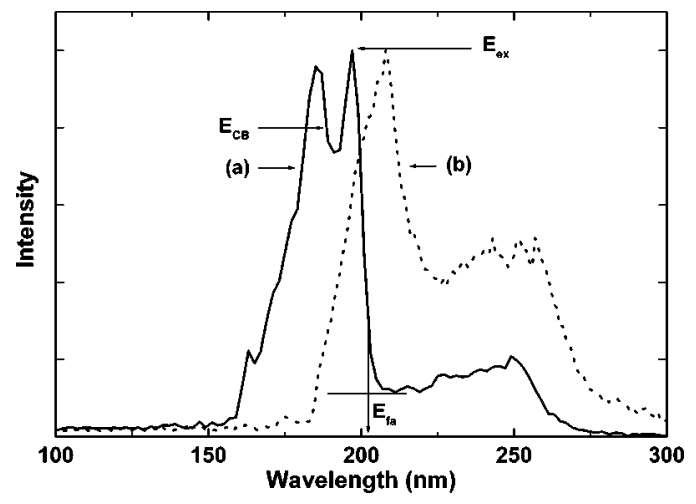

FIG. 6. Excitation spectra of (a) pure $\mathrm{K}_{2} \mathrm{LaCl}_{5}$ and (b) pure $\mathrm{K}_{2} \mathrm{LaBr}_{5}$ at $10 \mathrm{~K}$ monitoring STE luminescence at 415 and $400 \mathrm{~nm}$, respectively. 
TABLE I. Properties of undoped $\mathrm{LaX}_{3}, \mathrm{~K} X$, and $\mathrm{K}_{2} \mathrm{LaX}_{5}(X$ $=\mathrm{Cl}, \mathrm{Br}, \mathrm{I})$. Energies are in $\mathrm{eV}$ and wavelength $\lambda_{S T E}$ is in $\mathrm{nm}$. For $\lambda_{S T E}$ the emission wavelength of the spin-forbidden $\pi$-polarized transition is compiled.

\begin{tabular}{|c|c|c|c|c|c|}
\hline Compound & $E_{f a}$ & $E_{e x}$ & $E_{C B}$ & $\lambda_{S T E}$ & Ref. \\
\hline $\mathrm{LaCl}_{3}$ & 6.2 & 6.5 & $\approx 7$ & 405 & 22 \\
\hline $\mathrm{LaBr}_{3}$ & 5.2 & 5.4 & $\approx 5.6$ & 430 & this work \\
\hline $\mathrm{LaI}_{3}$ & 3.2 & & & & this work \\
\hline $\mathrm{KCl}$ & 7.5 & 7.8 & 8.7 & $537(\pi)$ & 24 \\
\hline $\mathrm{KBr}$ & 6.4 & 6.7 & 7.4 & $544(\pi)$ & 24 \\
\hline $\mathrm{KI}$ & 5.8 & 5.9 & 6.3 & $407(\pi)$ & 24 \\
\hline $\mathrm{K}_{2} \mathrm{LaCl}_{5}$ & 6.1 & 6.3 & 6.6 & 400 & this work \\
\hline $\mathrm{K}_{2} \mathrm{LaBr}_{5}$ & 4.9 & & & 440 & this work \\
\hline $\mathrm{K}_{2} \mathrm{LaI}_{5}$ & 3.9 & & & $\approx 480$ & this work \\
\hline
\end{tabular}

ferent energy values. The fundamental absorption $E_{f a}$ is the energy of the first sharp onset in the excitation or absorption spectrum of the pure compound. For $\mathrm{K}_{2} \mathrm{LaCl}_{5}$ this is $202 \mathrm{~nm}$ $(6.1 \mathrm{eV})$. The first maximum in the excitation spectrum of STE emission is attributed to the creation of free excitons that can be regarded as bound electron hole pairs. This exciton energy $E_{e x}$ is located at $197 \mathrm{~nm}(6.3 \mathrm{eV})$.

For $\mathrm{K}_{2} \mathrm{LaCl}_{5}$ the edge of the conduction band $E_{C B}$ is found at higher energy and corresponds to the creation of free electrons in the conduction band and free holes in the valence band. The second onset at $188 \mathrm{~nm}(6.6 \mathrm{eV})$ in the spectrum of $\mathrm{K}_{2} \mathrm{LaCl}_{5}$ is tentatively attributed to these across the band gap excitations. The data on band gap and exciton energies are compiled in Table I. Figure 6 also shows some excitation at energies below $E_{f a}$, which are attributed to $\mathrm{Ce}^{3+}$ impurities in the nominally pure compounds.

Excitation and emission spectra of $\mathrm{K}_{2} \mathrm{LaCl}_{5}: 0.1 \% \mathrm{Ce}^{3+}$ at $10 \mathrm{~K}$ are shown in Fig. 7 (solid traces). The excitation spectrum of the undoped compound is reported as dotted trace for comparison. The emission spectrum shows two maxima located at 344 and $372 \mathrm{~nm}$, due to transitions from the lowest energy level of the $\mathrm{Ce}^{3+} 5 d$ configuration to the

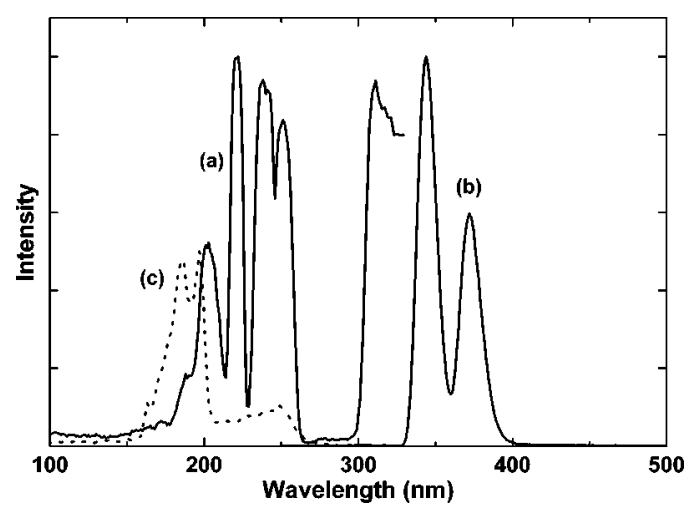

FIG. 7. (a) Excitation and (b) emission spectra of $\mathrm{K}_{2} \mathrm{LaCl}_{5}: 0.1 \% \mathrm{Ce}^{3+}$ at $10 \mathrm{~K}$. The excitation spectrum was measured at $\lambda_{e m}=372 \mathrm{~nm}$, the emission spectrum was measured under $\lambda=222 \mathrm{~nm}$ excitation. To compare, the excitation spectrum (c) of $415 \mathrm{~nm}$ emission in pure $\mathrm{K}_{2} \mathrm{LaCl}_{5}$ (dotted trace) is shown as well.
${ }^{2} \mathrm{~F}_{5 / 2}$ and ${ }^{2} \mathrm{~F}_{7 / 2}$ levels, respectively. Accordingly, the ${ }^{2} \mathrm{~F}$ spinorbit splitting is $2190 \mathrm{~cm}^{-1}$. In contrast to the $\mathrm{X}$-ray excited optical luminescence spectrum shown in Fig. 3, no STE emission is excited at $222 \mathrm{~nm}$.

In the excitation spectrum several bands can be distinguished. Four are located at 202, 221, 239, and $252 \mathrm{~nm}$. Another band between 300 and $350 \mathrm{~nm}$ is actually composed of two subbands with maxima at 313 and $335 \mathrm{~nm} .{ }^{20}$ Based on the low symmetry of the $\mathrm{La}^{3+}$ site $\left(\mathrm{C}_{s}\right)$, we expect a fivefold splitting of the $\mathrm{Ce}^{3+} 5 d$ levels. We assign the five lowest energy bands to the five $5 d$ levels of $\mathrm{Ce}^{3+}$. The data are compiled in Table II. The band at $202 \mathrm{~nm}(6.1 \mathrm{eV})$ is located just at lower energy than the exciton creation peak in the pure compound at $197 \mathrm{~nm}$. It is attributed to the creation of so-called impurity-trapped excitons, i.e., an exciton created in the vicinity of a $\mathrm{Ce}^{3+}$ ion.

In Fig. 8 the time-integrated and time-resolved excitation and emission spectra of $\mathrm{K}_{2} \mathrm{LaBr}_{5}: 0.7 \% \mathrm{Ce}^{3+}$ and of pure $\mathrm{K}_{2} \mathrm{LaBr}_{5}$ at $10 \mathrm{~K}$ are compared. The $\mathrm{Ce}^{3+} 5 d \rightarrow 4 f$ emission excited at $270 \mathrm{~nm}$ gives rise to two maxima at 357 and 388 $\mathrm{nm}$ [spectrum (e)]. Accordingly, the spin-orbit splitting of the ${ }^{2} \mathrm{~F}$ ground state of $\mathrm{Ce}^{3+}$ is $2240 \mathrm{~cm}^{-1}$. The time-integrated excitation spectrum monitoring the $5 d \rightarrow 4 f$ emission at 100 $\mathrm{K}$ is composed of two broadbands [spectrum (c)]. The band between 320 and $360 \mathrm{~nm}$ is composed of two subbands as in $\mathrm{K}_{2} \mathrm{LaCl}_{5}$. Spectrum (d) recorded with synchrotron radiation at $10 \mathrm{~K}$ shows the first band at $328 \mathrm{~nm}$ just before the instrumental limit was reached. The other band is assumed to be located around $345 \mathrm{~nm}$, see Table II. In spectrum (d) we observe further bands between 250 and $280 \mathrm{~nm}$. In the pure compound that contains trace impurities of $\mathrm{Ce}^{3+}$, see spectrum (b), these bands are better resolved and clearly show two maxima at 257 and $266 \mathrm{~nm}$. They are also attributed to $f d$ transitions in $\mathrm{Ce}^{3+}$, see Table II. The excitation peak at $294 \mathrm{~nm}$ in spectrum (c) may be related to an unknown impurity or to excitation of $\mathrm{Ce}^{3+}$ aggregates. The sharp decrease in excitation efficiency in spectrum (d) at wavelengths shorter than $255 \mathrm{~nm}(4.9 \mathrm{eV})$ is attributed to the onset of the fundamental absorption of the host crystal, see Table I. This steep drop in the $10 \mathrm{~K}$ spectrum is less pronounced in the $100 \mathrm{~K}$ spectrum (c) because the energy transfer form the host lattice to $\mathrm{Ce}^{3+}$ ions becomes more efficient at elevated temperatures. The fifth $\mathrm{Ce}^{3+} f d$ excitation peak remains unidentified and is probably located at shorter wavelengths than the onset of the fundamental absorption at $255 \mathrm{~nm}$.

The excitation spectrum of STE emission in pure $\mathrm{K}_{2} \mathrm{LaBr}_{5}$, see Fig. 6 curve (b) and Fig. 8 curve (a), does not show clear thresholds and peaks that are required to determine $E_{f a}, E_{e x}$, and $E_{C B}$. This might be due to a poor efficiency of STE creation under across band gap excitation, but also due to the creation of impurity trapped excitons at energies below the fundamental absorption onset, since the nominally pure compounds contain impurities. In this case the sharp drop in excitation efficiency of the $\mathrm{Ce}^{3+}$-doped compound at $255 \mathrm{~nm}$ marks $E_{f a}$.

The excitation and emission spectra of $\mathrm{K}_{2} \mathrm{LaI}_{5}: 0.7 \%$ $\mathrm{Ce}^{3+}$ at $100 \mathrm{~K}$ are shown in Fig. 9. The emission spectrum 
TABLE II. Spectroscopic and crystallographic properties of $\mathrm{Ce}^{3+}$-doped $\mathrm{LaX}_{3}$ and $\mathrm{K}_{2} \mathrm{LaX}_{5}$, and $\mathrm{Eu}^{2+}$-doped $\mathrm{KX}(X=\mathrm{Cl}, \mathrm{Br}, \mathrm{I}) .\left(N: R_{\mathrm{av}}\right)$ represents anion coordination number and average distance to the anions (pm). Type of polyhedron (poly) and point symmetry (sym) at the Ce or Eu site are given. Values between brackets are estimated values.

\begin{tabular}{|c|c|c|c|c|c|c|}
\hline Compound & $\left(N: R_{\mathrm{av}}\right)$ & (poly:sym) & $5 d$-excitation bands $(\mathrm{nm})$ & $\epsilon_{\mathrm{c}}\left(\mathrm{cm}^{-1}\right)$ & $\epsilon_{\mathrm{cfs}}\left(\mathrm{cm}^{-1}\right)$ & Ref. \\
\hline $\mathrm{LaCl}_{3}$ & $(9: 295)$ & $\left(3 \mathrm{ctp}: C_{3 h}\right)$ & $243,250,263,274,281$ & 13000 & 5565 & 22,9 \\
\hline $\mathrm{LaBr}_{3}$ & $(9: 312)$ & $\left(3 \mathrm{ctp}: C_{3 h}\right)$ & $260,270,284,299,308$ & 15906 & 5994 & this work \\
\hline $\mathrm{LaI}_{3}$ & $(8: 334)$ & $\left(2 \mathrm{ctp}: \mathrm{C}_{2 v}\right)$ & 420 & & & this work \\
\hline $\mathrm{KCl}: \mathrm{Eu}^{2+}$ & $(6: 315)$ & $\left(\right.$ octa: $\left.O_{h}\right)$ & $2 \times(250), 3 \times(357)$ & & 12000 & 32 \\
\hline $\mathrm{KBr}: \mathrm{Eu}^{2+}$ & $(6: 329)$ & (octa: $\left.O_{h}\right)$ & $2 \times(257), 3 \times(357)$ & & 10900 & 32,33 \\
\hline $\mathrm{KI}: \mathrm{Eu}^{2+}$ & $(6: 353)$ & $\left(\right.$ octa: $\left.O_{h}\right)$ & $2 \times(266), 3 \times(357)$ & & 9500 & 32 \\
\hline $\mathrm{K}_{2} \mathrm{LaCl}_{5}$ & $(7: 284)$ & $\left(1 \mathrm{ctp}: C_{s}\right)$ & $221,239,252,313,335$ & 13500 & 15400 & this work \\
\hline $\mathrm{K}_{2} \mathrm{LaBr}_{5}$ & $(7: 299)$ & $\left(1 \mathrm{ctp}: C_{s}\right)$ & $(235), 257,266,328,345$ & $(15500)$ & $(13600)$ & this work \\
\hline $\mathrm{K}_{2} \mathrm{LaI}_{5}$ & $(7: 323)$ & $\left(1 \mathrm{ctp}: C_{s}\right)$ & $(263),(280),(300), 365,380$ & $(19100)$ & $(11700)$ & this work \\
\hline
\end{tabular}

(b) is dominated by the characteristic doublet of $\mathrm{Ce}^{3+} 5 d$ $\rightarrow 4 f$ emission with peak positions at 399 and $437 \mathrm{~nm}$. Accordingly, the ${ }^{2} \mathrm{~F}$ spin-orbit splitting of the ground state of $\mathrm{Ce}^{3+}$ is $2180 \mathrm{~cm}^{-1}$. The excitation spectrum (a) shows a broadband between 350 and $400 \mathrm{~nm}$, which resembles similar bands observed for $\mathrm{K}_{2} \mathrm{LaCl}_{5}$ and $\mathrm{K}_{2} \mathrm{LaBr}_{5}$. Following the results for $\mathrm{K}_{2} \mathrm{LaCl}_{5}$ the broadband is attributed to an unresolved doublet located at approximately 365 and $380 \mathrm{~nm}$, see Table II. The increasing excitation efficiency at wavelengths shorter than $320 \mathrm{~nm}(3.9 \mathrm{eV})$ is attributed to host lattice excitation.

The optical properties of $\mathrm{LaCl}_{3}: \mathrm{Ce}^{3+}$ have already been published $^{9,22}$ and data are included to Tables I and II. Figure 10 shows the optical excitation, curve (a), and emission, curve (b), spectrum of $\mathrm{LaBr}_{3}: 0.5 \% \mathrm{Ce}^{3+}$. The $\mathrm{Ce}^{3+} 5 d$ $\rightarrow 4 f$ emissions are located at 355 and $390 \mathrm{~nm}$. Very similar to $\mathrm{K}_{2} \mathrm{LaBr}_{5}: \mathrm{Ce}^{3+}$. But in contrast to the ternary halides, the five $\mathrm{Ce}^{3+} 5 d$ levels at 260, 270, 284, 299, and $308 \mathrm{~nm}$ in the excitation spectrum of $\mathrm{LaBr}_{3}: \mathrm{Ce}^{3+}$ are nicely resolved, see Table II. Alike $\mathrm{K}_{2} \mathrm{LaCl}_{5}: \mathrm{Ce}^{3+}$, just below the onset of the

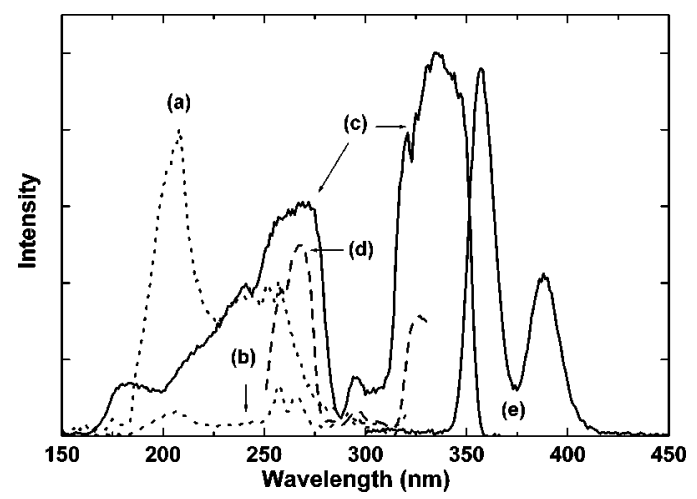

FIG. 8. (a) Slow (106 ns time gate) excitation spectrum of 400 nm emission in undoped $\mathrm{K}_{2} \mathrm{LaBr}_{5}$. (b) Fast (27 ns time gate) excitation spectrum of $355 \mathrm{~nm}$ emission in undoped $\mathrm{K}_{2} \mathrm{LaBr}_{5}$. (c) Timeintegrated excitation spectrum of $\mathrm{Ce}^{3+} d f$ emission in $\mathrm{K}_{2} \mathrm{LaBr}_{5}: 0.7 \% \mathrm{Ce}^{3+}$ at $100 \mathrm{~K}$. (d) Fast (27 ns time gate) excitation spectrum of $\mathrm{Ce}^{3+} d f$ emission in $\mathrm{K}_{2} \mathrm{LaBr}_{5}: 0.7 \% \mathrm{Ce}^{3+}$ at $10 \mathrm{~K}$. (e) Time-integrated emission spectrum in $\mathrm{K}_{2} \mathrm{LaBr}_{5}: 0.7 \% \mathrm{Ce}^{3+}$ at 270 $\mathrm{nm}$ excitation at $100 \mathrm{~K}$. fundamental absorption $E_{f a}$ at $238 \mathrm{~nm}(5.2 \mathrm{eV})$ a clear peak is observed at $244 \mathrm{~nm}$, which is attributed to impuritytrapped excitons. In the undoped $\mathrm{LaBr}_{3}$ excitation spectrum, curve (c), both the $\mathrm{Ce}^{3+} f d$ bands and the impurity-trapped excitons are absent. $\mathrm{LaI}_{3}: \mathrm{Ce}^{3+}$ was studied too, but its spectroscopy is still incomplete. The two $\mathrm{Ce}^{3+} d f$ emission bands are located at 450 and $500 \mathrm{~nm}$. The first $f d$ excitation band of $\mathrm{Ce}^{3+}$ was detected at $420 \mathrm{~nm}$, but the four higher-lying ones are above the fundamental absorption edge of $\mathrm{LaI}_{3}$ at $3.2 \mathrm{eV}$, and thus not accesssible.

\section{Scintillation decay}

Scintillation decay spectra of pure $\mathrm{K}_{2} \mathrm{LaX}_{5}(X=\mathrm{Cl}, \mathrm{Br}, \mathrm{I})$ at room temperature, excited with $662 \mathrm{keV} \gamma$ rays from a ${ }^{137} \mathrm{Cs}$ source are shown in Fig. 11. The rising slope before $t=0$ is due to an experimental artifact and has no physical meaning. The spectra represent the luminescence intensity of the STE that decays exponentially as a function of time. The lifetime of the STE decreases along the series $\mathrm{Cl} \rightarrow \mathrm{Br} \rightarrow \mathrm{I}$, in accordance with former observations on the alkali halides. ${ }^{23}$ It is about $3.7 \mu \mathrm{s}$ in the chloride, $2.2 \mu \mathrm{s}$ in the bromide, and $350 \mathrm{~ns}$ in the iodide. These lifetimes do not necessarily represent the intrinsic lifetime of the STE, but can also be the

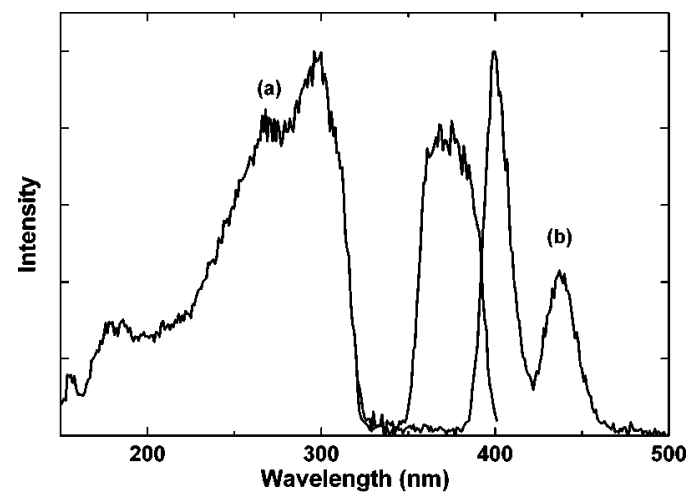

FIG. 9. (a) Excitation spectrum monitoring $\mathrm{Ce}^{3+}$ emission at $\lambda_{e m}=440 \mathrm{~nm}$ and (b) emission spectrum excited at $\lambda_{e x}=310 \mathrm{~nm}$ of $\mathrm{K}_{2} \mathrm{LaI}_{5}: 0.7 \% \mathrm{Ce}^{3+}$ at $100 \mathrm{~K}$. 


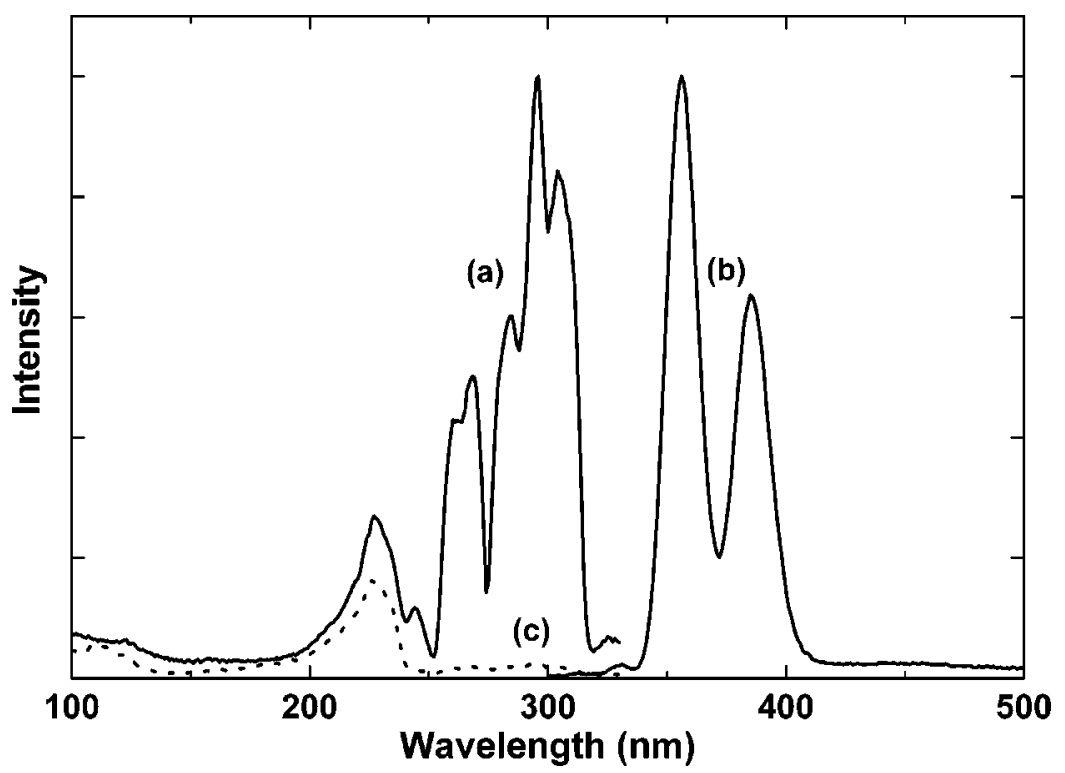

FIG. 10. (a) Excitation spectrum monitoring $\mathrm{Ce}^{3+}$ emission at $\lambda_{e m}=360 \mathrm{~nm}$ and (b) emission spectrum excited at $\lambda_{e x}=295 \mathrm{~nm}$ of $\mathrm{LaBr}_{3}: 0.5 \%$ $\mathrm{Ce}^{3+}$ at $10 \mathrm{~K}$. To compare, the excitation spectrum (c) of the STE emission in pure $\mathrm{LaBr}_{3}$ (dotted trace) is shown as well.

result of the quenching of STE luminescence at room temperature by energy migration to traps.

Figure 12 shows the scintillation decay spectra of (a) $\mathrm{K}_{2} \mathrm{LaCl}_{5}: 0.1 \% \mathrm{Ce}^{3+}$, (b) $\mathrm{K}_{2} \mathrm{LaBr}_{5}: 0.7 \% \mathrm{Ce}^{3+}$, and (c) $\mathrm{K}_{2} \mathrm{LaI}_{5}: 0.7 \% \mathrm{Ce}^{3+}$ at room temperature. In each case, the scintillation emission is a combination of much $\mathrm{Ce}^{3+}$ and few STE emission, see, e.g., Fig. 3. For $\mathrm{K}_{2} \mathrm{LaCl}_{5}: 0.1 \% \mathrm{Ce}^{3+}$ the scintillation decay profile closely resembles the spectrum of the pure compound. Despite the fact that most part of the emission originates from $\mathrm{Ce}^{3+},{ }^{20}$ the luminescence intensity decays exponentially with a slow decay time of about $3 \mu \mathrm{s}$. We assume that this represents the lifetime of the STE involved in the energy transfer from the host lattice to $\mathrm{Ce}^{3+}$. In the first $100 \mathrm{~ns}$ after the excitation pulse $\mathrm{K}_{2} \mathrm{LaCl}_{5}: 0.1 \%$ $\mathrm{Ce}^{3+}$ shows an additional decay component. Its contribution to the total luminescence intensity is rather small but it increases for higher $\mathrm{Ce}$ concentrations. ${ }^{20}$

The scintillation decay of $\mathrm{K}_{2} \mathrm{LaBr}_{5}: 0.7 \% \mathrm{Ce}^{3+}$ also consists of two components. The faster one dominates the first $0.5 \mu \mathrm{s}$ and the slower one has a lifetime of $1.4 \mu \mathrm{s}$. Again the latter represents the lifetime of the STE. Finally,

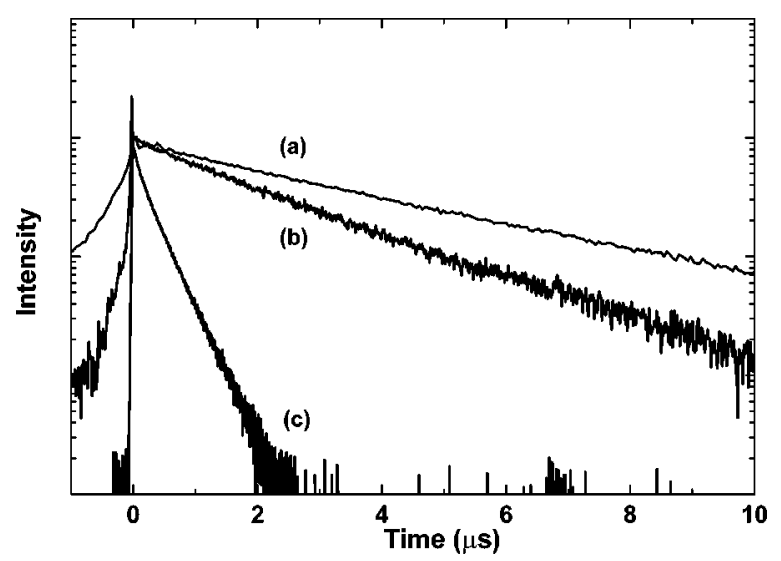

FIG. 11. Scintillation decay time spectra of (a) $\mathrm{K}_{2} \mathrm{LaCl}_{5}$, (b) $\mathrm{K}_{2} \mathrm{LaBr}_{5}$, and (c) $\mathrm{K}_{2} \mathrm{LaI}_{5}$ at room temperature.
$\mathrm{K}_{2} \mathrm{LaI}_{5}: 0.7 \% \mathrm{Ce}^{3+}$ shows a single fast exponential decay with a lifetime of $24 \pm 1 \mathrm{~ns}$. It is characteristic for the parity allowed $\mathrm{Ce}^{3+} 5 d \rightarrow 4 f$ transition. This fast decay component contains more than $90 \%$ of the total luminescence intensity. Apparently, the scintillation decay rates of $\mathrm{K}_{2} \mathrm{LaX}_{5}: \mathrm{Ce}^{3+}$ drastically increase along the halide series from $\mathrm{Cl}$ to $\mathrm{I}$.

\section{DISCUSSION}

We first discuss the spectroscopic properties of the pure and $\mathrm{Ce}^{3+}$-doped compounds with emphasis on the effects of anion variation. Next the scintillation mechanism of $\mathrm{K}_{2} \mathrm{LaX}_{5}: \mathrm{Ce}^{3+}(X=\mathrm{Cl}, \mathrm{Br}, \mathrm{I})$ are discussed and compared with those of $\mathrm{LaX}_{3}: \mathrm{Ce}^{3+}$.

\section{A. Spectroscopic properties}

\section{Pure compounds}

Table I compiles $E_{f a}, E_{e x}$, and $E_{C B}$ of the undoped crystals of $\mathrm{LaX}_{3}, \mathrm{KX}$, and $\mathrm{K}_{2} \mathrm{LaX} X_{5}$. In addition, the emission wavelength of the self-trapped exciton is given. One may notice the following trends.

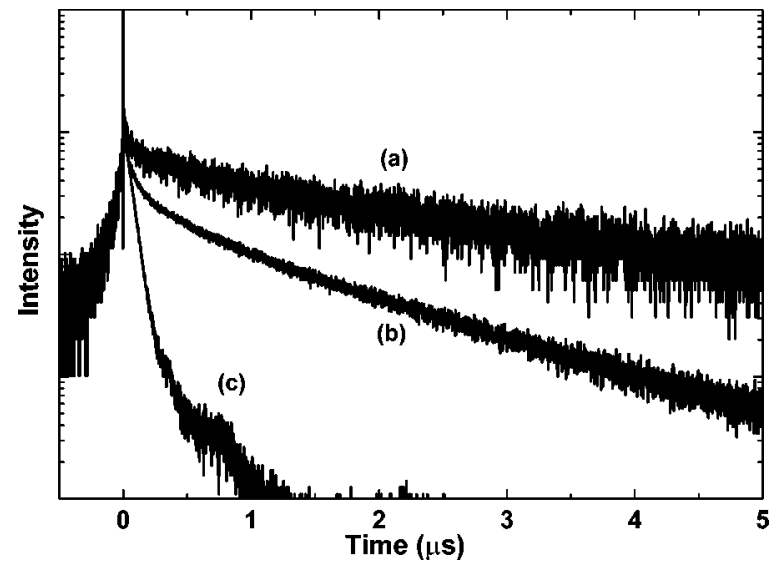

FIG. 12. Scintillation decay time spectra of (a) $\mathrm{K}_{2} \mathrm{LaCl}_{5}: 0.1 \%$ $\mathrm{Ce}^{3+}$, (b) $\mathrm{K}_{2} \mathrm{LaBr}_{5}: 0.7 \% \mathrm{Ce}^{3+}$, and (c) $\mathrm{K}_{2} \mathrm{LaI}_{5}: 0.7 \% \mathrm{Ce}^{3+}$ at room temperature. 
(1) All three energies decrease in the sequence $\mathrm{Cl} \rightarrow \mathrm{Br}$ $\rightarrow$ I. This is obviously related to the decreasing electronbinding energy of the anion, which is also expressed by the Pauling electronegativity $\chi$, i.e., 3.16, 2.96, and 2.66 for $\mathrm{Cl}$, $\mathrm{Br}$, and I, respectively.

(2) The tabulated energies of the alkali halides are larger than for the lanthanide halides. This must be attributed to the different Madelung potential at the trivalent $\mathrm{La}^{3+}$ site as compared to that at the monovalent $\mathrm{K}^{+}$site.

(3) The energies of the $\mathrm{K}_{2} \mathrm{La} X_{5}$ materials resemble those of $\mathrm{LaX}_{3}$. This illustrates that the bottom of the conduction band in both type of materials is formed by $\mathrm{La}^{3+}$ orbitals.

(4) For the potassium halides, the exciton-binding energy $E_{C B}-E_{e x}$ decreases in the sequence $\mathrm{Cl} \rightarrow \mathrm{Br} \rightarrow \mathrm{I}$. This also holds for the alkali halides involving $\mathrm{Li}, \mathrm{Na}, \mathrm{Rb}$, and $\mathrm{Cs}^{24}{ }^{24} \mathrm{It}$ is caused by the increasingly larger polarizability of the anion leading to a screening of the hole component of the exciton and larger effective mass $m^{*}$ of the hole. Although it cannot be verified from the results in Table I, we expect for $\mathrm{LaX}_{3}$ and $\mathrm{K}_{2} \mathrm{La} X_{5}$ a similar behavior.

Despite that the exciton peak $E_{e x}$ shifts 2-3 eV with type of anion in each class of compound, the position of the STE emission band does not change more than $0.4 \mathrm{eV}$ in $\mathrm{K}_{2} \mathrm{LaX} X_{5}$ (see Fig. 2) and $\mathrm{LaX}_{3}$. Also in the alkali halides the anion does not have a large influence on the STE emission. Change of alkali cation from $\mathrm{Na}^{+}$to $\mathrm{K}^{+}$or $\mathrm{Rb}^{+}$has a much larger influence on the position of the STE emission band. ${ }^{23}$ In these systems the energy of the STE emission band tends to decrease in the series $\mathrm{Na}^{+}$to $\mathrm{K}^{+}$to $\mathrm{Rb}^{+}$.

\section{2. $\mathrm{Ce}^{3+}$ spectroscopy}

For the free $\mathrm{Ce}^{3+}$ ion, the $5 d$ configuration is located at an average energy of $51230 \mathrm{~cm}^{-1} .{ }^{8}$ Due to the spin-orbit interaction two energy levels, i.e., ${ }^{2} \mathrm{D}_{3 / 2}$ and ${ }^{2} \mathrm{D}_{5 / 2}$, are observed. Note, in this section we will use, as is commonly done so in spectroscopy, the inverse wavelength in $\mathrm{cm}^{-1}$ as the unit of energy $\left(1 \mathrm{eV}=8065 \mathrm{~cm}^{-1}\right)$.

In a crystalline environment, the average energy of the $5 d$ configuration is reduced by the centroid shift, $\epsilon_{c}$. Depending on the site symmetry the degeneracy might be lifted and up to five distinct $5 d$ energy levels are obtained. The energy difference between the lowest and highest $5 d$ level is defined as the total crystal field splitting $\epsilon_{\text {cfs }}$. Table II compiles the wavelengths $\lambda_{i}$ of the five $4 f \rightarrow 5 d$ excitation bands of $\mathrm{Ce}^{3+}$ in the $\mathrm{LaX}_{3}$ and $\mathrm{K}_{2} \mathrm{La} X_{5}$ compounds.

Figure 13 illustrates how the $5 d$ crystal field splitting in $\mathrm{Ce}^{3+}$ varies with the shape and size of the anion coordination polyhedron around $\mathrm{Ce}^{3+}$. The size of the polyhedron is modeled by the average distance $R_{a v}$ of the cation to the $N$ coordinating anions, see column 2 in Table II. A correction of $0.6 \Delta R$ was applied to account for the lattice relaxation. $\Delta R$ is defined as the difference in ionic radius between $\mathrm{Ce}^{3+}$ and the cation it substitutes for. It amounts to 2, 3, and $37 \mathrm{pm}$ for $\mathrm{La}_{3}, \mathrm{~K}_{2} \mathrm{La} X_{5}$, and $\mathrm{K} X$, respectively. Empirically, $\epsilon_{\text {cfs }}$ can be modeled by Eq. (1):

$$
\epsilon_{\mathrm{cfs}}=\beta_{\text {poly }} R_{a v}^{-2},
$$

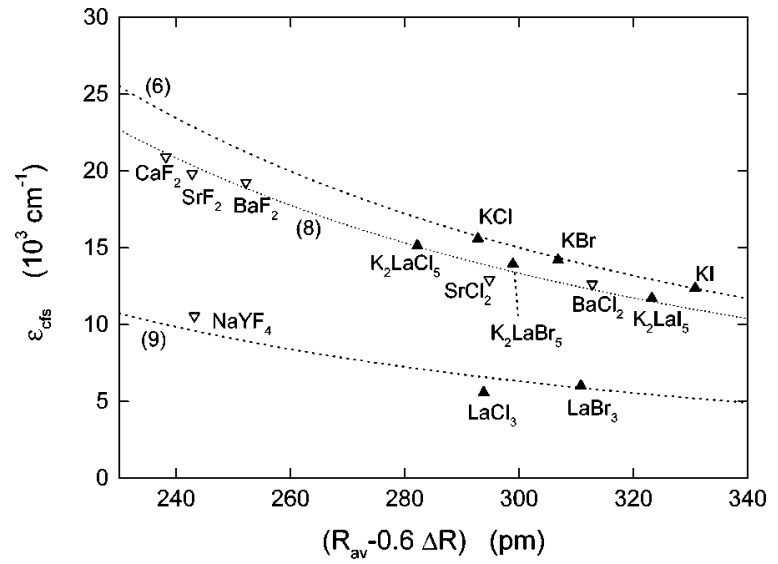

FIG. 13. The crystal field splitting $\epsilon_{\text {cfs }}$ of the $\mathrm{Ce}^{3+} 5 d$ configuration in compounds as a function of the average distance to neighboring anions in the relaxed lattice. Dashed curves marked (6), (8), and (9) pertain to sixfold octahedral, eightfold cubic, and ninefold tricapped trigonal prism coordination. Values for $\mathrm{KCl}, \mathrm{KBr}$, and $\mathrm{KI}$ are anticipated from $\mathrm{Eu}^{2+}$ data.

where $\beta_{\text {poly }}$ is a constant depending on the shape of the coordination polyhedron. ${ }^{10}$ The validity of Eq. (1) for $\mathrm{CaF}_{2}$, $\mathrm{SrF}_{2}, \mathrm{BaF}_{2}, \mathrm{SrCl}_{2}$, and $\mathrm{BaCl}_{2}$ with eightfold cubic coordination, and $\mathrm{NaYF}_{4}, \mathrm{LaCl}_{3}$, and $\mathrm{LaBr}_{3}$ with ninefold tricapped trigonal prismatic (3ctp) coordination is demonstrated by the dashed lines in Fig. 13.

The total crystal field splitting in $\mathrm{K}_{2} \mathrm{LaCl}_{5}$ is about the same as the value typical for cubic coordination, see Fig. 13. Information on $\mathrm{K}_{2} \mathrm{LaBr}_{5}$ and $\mathrm{K}_{2} \mathrm{LaI}_{5}$ is still incomplete, but reasonable estimates for the missing $5 d$ level energies can be given. The type of coordination polyhedron in the $\mathrm{K}_{2} \mathrm{LaX}{ }_{5}$ compounds are the same, and then an $R^{-2}$ dependence with polyhedral size is expected. Employing Eq. (1) the total crystal field splitting and from that the wavelengths of the missing $5 d$ bands were estimated. They are given together with the values for the centroid shift $\epsilon_{\mathrm{c}}$ within brackets in columns $4-6$ of Table II.

Information is not available on the energy of $\mathrm{Ce}^{3+} 5 d$ levels in the $\mathrm{KX}$ type of compounds. However, it can be estimated from the results available on the energies of the $4 f^{6} 5 d$ levels of $\mathrm{Eu}^{2+}$ in these compounds. The $5 d$ levels of $\mathrm{Eu}^{2+}$ at sites with octahedral (octa) coordination are split into a low-energy triplet and a high-energy doublet state separated by an energy known as the $10 D q$ value, which can be set equal to $\epsilon_{\mathrm{cfs}}$. From previous studies it is known that the crystal field splitting in $\mathrm{Eu}^{2+}$ is about 0.77 times that in $\mathrm{Ce}^{3+} \cdot{ }^{10}$ Using this ratio, the data anticipated for $\mathrm{Ce}^{3+}$-doped $\mathrm{K} X$ compounds is drawn in Fig. 13.

We now observe that the (anticipated) crystal field splitting in the $\mathrm{K}_{2} \mathrm{LaX}{ }_{5}$ compounds falls between that of octahedral and cubic coordination. This agrees with the general trend of decreasing crystal field splitting with larger coordination number $N$ around $\mathrm{Ce}^{3+}$. It is largest for octahedral coordination with $N=6$. Provided that the so-called prismatic angle remains the same, the crystal field splitting for a trigonal prism coordination is the same as for octahedral coordination. ${ }^{10,25}$ Adding one capping anion on one of the 
three side faces of a trigonal prism, as in $\mathrm{K}_{2} \mathrm{LaX}_{5}$, leads to a smaller crystal field splitting, but apparently still somewhat larger than that of cubic coordination. When all three side faces of the trigonal prism are capped with an anion, one obtains the situation in $\mathrm{NaYF}_{4}, \mathrm{LaCl}_{3}$, and $\mathrm{LaBr}_{3}$ with much reduced crystal field splitting. Note that the changing chemical properties of the anions in the sequence $\mathrm{Cl}$ to $\mathrm{Br}$ to $\mathrm{I}$ are not important for the crystal field splitting. Only the change in ionic radius appears via $R_{a v}$ in Eq. (1).

On the other hand, for fluorides, chlorides, bromides, and iodides, $\epsilon_{c}$ is typically $6000 \mathrm{~cm}^{-1}, \quad 14000 \mathrm{~cm}^{-1}$, $16000 \mathrm{~cm}^{-1}$, and $19000 \mathrm{~cm}^{-1}$, respectively. This is also revealed in Table II

\section{B. STE and scintillation properties}

When the electron and hole components of a STE recombine, STE luminescence is observed. This luminescence usually arises from a spin-forbidden transitions made partly allowed by the halogen spin-orbit interaction of the $V_{K}$ core of the STE, but still the decay time is relatively large.

On the other hand, the $\mathrm{Ce}^{3+} 5 d \rightarrow 4 f$ emission is spin and dipole allowed and has a short decay time of (2-6) $\times 10^{-8}$ s. After absorbing a $\gamma$-ray quantum in the host crystal, free electrons and holes are created in the conduction band and valence band, respectively. If these free electrons and holes are trapped promptly by a $\mathrm{Ce}^{3+}$ ion before STE formation, the scintillation decay time will be the same as the characteristic lifetime of the $5 d$ excited state of $\mathrm{Ce}^{3+}$. This is the situation at room temperature in $\mathrm{LaBr}_{3}: 0.5 \% \mathrm{Ce}^{3+}$ and in $\mathrm{K}_{2} \mathrm{LaI}_{5}: 0.7 \% \mathrm{Ce}^{3+}$, e.g., Fig. 12(c). Otherwise, slow scintillation is observed due to STE luminescence and energy transfer from the (migrating) STE towards $\mathrm{Ce}^{3+}$.

As can be seen from Fig. 11, the lifetime of the STE tends to become shorter in the series $\mathrm{Cl} \rightarrow \mathrm{Br} \rightarrow \mathrm{I}$. This can be satisfactorly accounted for in terms of the larger spin-orbit interaction in the heavier halides, ${ }^{26}$ leading to a more allowed transition. However, the smaller values for the lifetime of the STE can also be explained by the increasing thermally activated hopping rate of the STE in the series $\mathrm{Cl} \rightarrow \mathrm{Br} \rightarrow \mathrm{I} .{ }^{27,28} \mathrm{It}$ leads to quenching of STE emission and decreasing lifetime due to the energy transfer to defects or $\mathrm{Ce}^{3+}$.

In principle, there are several energy transfer mechanisms possible that may account for the observed correlation between the decay time of the scintillation pulse and the type of anion. In the case of STE diffusion, the luminescence of $\mathrm{K}_{2} \mathrm{LaX}_{5}: \mathrm{Ce}^{3+}(X=\mathrm{Cl}, \mathrm{Br}, \mathrm{I})$ at low temperatures is largely due to the radiative recombination of the STE, see Fig. 3. However, as the temperature rises the mobility of the STE increases as well, and the energy is transferred to a $\mathrm{Ce}^{3+}$ center when the STE encounters a $\mathrm{Ce}^{3+}$ ion. Such an energy transfer can explain the observed anticorrelation of $\mathrm{Ce}^{3+}$ and STE luminescence intensity in Figs. 4 and 5 between 100 and $400 \mathrm{~K}$. If we consider the migration of a $V_{K}$ center through the lattice, the activation energy for $V_{K}$ diffusion decreases from $\mathrm{Cl}$ to I. ${ }^{29-31} \mathrm{In}$ the same order the mobility of the STE increases. Indeed, the scintillation decay time decreases from $\mathrm{K}_{2} \mathrm{LaCl}_{5}: 0.1 \% \mathrm{Ce}^{3+}$ (Ref. 20) to $\mathrm{K}_{2} \mathrm{LaBr}_{5}: 0.7 \% \mathrm{Ce}^{3+}$ to $\mathrm{K}_{2} \mathrm{LaI}_{5}: 0.7 \% \mathrm{Ce}^{3+}$ (see Fig. 12).

\section{SUMMARY AND CONCLUSIONS}

In this work the spectroscopic properties and scintillation mechanism of undoped and $\mathrm{Ce}^{3+}$-doped $\mathrm{K}_{2} \mathrm{LaX}_{5}, \mathrm{LaX}_{3}$, and $\mathrm{K} X(X=\mathrm{Cl}, \mathrm{Br}, \mathrm{I})$ have been determined and compared with each other. The band gap $E_{C B}$, the energy of the exciton peak $E_{e x}$, and the wavelength of STE emission $\lambda_{\text {STE }}$ are very similar for $\mathrm{K}_{2} \mathrm{LaX}_{5}$ and $\mathrm{La} X_{3}$, but much different from $\mathrm{K} X$. The conduction band levels of $\mathrm{La}^{3+}$ are at $1-2 \mathrm{eV}$ lower energy than those of $\mathrm{K}^{+}$. The decreasing binding strength for electrons along the halide series results in a band gap reduction of about $2 \mathrm{eV}$ from $\mathrm{Cl}$ to $\mathrm{I}$ in each series of compounds.

The energy of the five $f d$ transitions of $\mathrm{Ce}^{3+}$ in $\mathrm{LaX}_{3}$ and $\mathrm{K}_{2} \mathrm{LaX}_{5}$ compounds was determined by excitation and emission spectroscopy. The highest energy transitions of $\mathrm{K}_{2} \mathrm{LaBr}_{5}$ and $\mathrm{K}_{2} \mathrm{LaI}_{5}$ are located beyond the fundamental absorption of the host crystals. For those cases the energies were estimated based on empirical data from other $\mathrm{Ce}^{3+}$-doped compounds. Since $\mathrm{Ce}^{3+}$-doped $\mathrm{KX}$ has not been studied, the $\mathrm{Ce}^{3+} 5 d$ crystal field splitting was derived from data on $\mathrm{Eu}^{2+}$-doped $\mathrm{KX}$. For a given $\mathrm{Ce}^{3+}$ coordination, the increasing ionic radius of the anions from $\mathrm{Cl}$ to I causes a $20 \%$ decrease of the crystal field splitting. On the other hand, the centroid shift of the $5 d$ configuration increases in the sequence $\mathrm{Cl}, \mathrm{Br}$, I, due to larger covalency between anion and $\mathrm{Ce}^{3+}$ and due to larger polarizability of the anion.

Across the bandgap excitations either by $\mathrm{x}$ rays, $\gamma$ rays, or synchrotron radiation result in a combination of $\mathrm{Ce}^{3+} 5 d$ $\rightarrow 4 f$ and STE emission. The ratio of $\mathrm{Ce}^{3+}$ to STE emission intensity depends on temperature and $\mathrm{Ce}^{3+}$ concentration. Clear trends are observed. For low concentrations of $0.2-$ $0.5 \%$ and increasing temperature from 100 to $400 \mathrm{~K}$, the $\mathrm{Ce}^{3+}$ emission gains intensity at the expense of the STE emission. This is very clear for $\mathrm{LaCl}_{3}$ and $\mathrm{K}_{2} \mathrm{LaCl}_{5}$ where the STE emission dominates at $100 \mathrm{~K}$, and it is fully transferred to the $\mathrm{Ce}^{3+}$ emission at $400 \mathrm{~K}^{20,18}$ At room temperature both emissions are still present. Along the series $\mathrm{Cl}, \mathrm{Br}$, I the intensity of the $\mathrm{Ce}^{3+}$ emission increases at the expense of STE emission. In $\mathrm{LaBr}_{3}$ and $\mathrm{K}_{2} \mathrm{LaI}_{5}$ with $0.2-0.5 \% \mathrm{Ce}^{3+}$, the STE emission is very weak at room temperature and only fast $\mathrm{Ce}^{3+} d f$ emission is observed. These two compounds provide efficient and fast scintillators already at small $\mathrm{Ce}^{3+}$ concentrations. $\mathrm{LaCl}_{3}$ and $\mathrm{K}_{2} \mathrm{LaCl}_{5}$ are fast and efficient scintillators only when the $\mathrm{Ce}^{3+}$ concentration is increased above $10 \%$. The increase of $\mathrm{Ce}^{3+}$ scintillation efficiency and scintillation speed along the series from $\mathrm{Cl}$ to $\mathrm{I}$ is attributed to (1) an increasing hopping mobility of STEs and (2) the higher trapping rate of free electrons and holes by $\mathrm{Ce}^{3+}$ relative to the STE creation rate.

\section{ACKNOWLEDGMENTS}

This work was supported by the Netherlands Technology Foundation (STW), the Swiss National Science Foundation, IHP Contract No. HPRI-CT-1990-00040 of the European Commission, and Saint-Gobain Cristeaux et Détecteurs. 
${ }^{1}$ A.J. Wojtowicz, M. Balcerzyk, E. Berman, and A. Lempicki, Phys. Rev. B 49, 14880 (1994).

${ }^{2}$ A.J. Wojtowicz, P. Szupryczynski, J. Glodo, W. Drozdowski, and D. Wisniewski, J. Phys.: Condens. Matter 12, 4097 (2000).

${ }^{3}$ A. Lempicki and J. Glodo, Nucl. Instrum. Methods Phys. Res. A 416, 333 (1998).

${ }^{4}$ C. Pedrini, C. Dujardin, J.C. Gacon, A.N. Belsky, A.N. Vasilev, and A.G. Petrosyan, Radiat. Eff. Defects Solids 154, 277 (2001).

${ }^{5}$ E.V.D. van Loef, P. Dorenbos, C.W.E. van Eijk, K. Krämer, and H.U. Güdel, Appl. Phys. Lett. 77, 1467 (2000).

${ }^{6}$ E.V.D. van Loef, P. Dorenbos, C.W.E. van Eijk, K. Krämer, and H.U. Güdel, Appl. Phys. Lett. 79, 1573 (2001).

${ }^{7}$ E.V.D. van Loef, P. Dorenbos, and C.W.E. van Eijk, J. Phys.: Condens. Matter 15, 1367 (2003).

${ }^{8}$ P. Dorenbos, Phys. Rev. B 62, 15640 (2000).

${ }^{9}$ P. Dorenbos, Phys. Rev. B 62, 15650 (2000).

${ }^{10}$ P. Dorenbos, J. Alloys Compd. 341, 156 (2002).

${ }^{11}$ R.T. Williams and K.S. Song, J. Phys. Chem. Solids 51, 679 (1990).

${ }^{12}$ G. Meyer, Inorg. Synth. 25, 146 (1989).

${ }^{13}$ J.B. Reed, B.S. Hopkins, and L.F. Audrieth, Inorg. Synth. 1, 28 (1936)

${ }^{14} \mathrm{G}$. Meyer, Synthesis of Lanthanide and Actinide Compounds, edited by G. Meyer and L. Morss (Kluwer, Dordrecht, 1991), p. 145.

${ }^{15}$ G. Meyer, J. Soose, A. Moritz, V. Vitt, and Th. Holljes, Z. Anorg. Allg. Chem. 521, 161 (1985).

${ }^{16}$ G. Zimmerer, Nucl. Instrum. Methods Phys. Res. A 308, 178 (1991).

${ }^{17}$ W.W. Moses, Nucl. Instr. Meth. A 336, 253 (1993).

${ }^{18}$ O. Guillot-Noël, J.T.M. de Haas, P. Dorenbos, C.W.E. van Eijk,
K. Krämer, and H.U. Güdel, J. Lumin. 85, 21 (1999).

${ }^{19}$ E.V.D. van Loef, P. Dorenbos, C.W.E. van Eijk, K. Krämer, and H.U. Güdel, IEEE Trans. Nucl. Sci. 48, 341 (2001).

${ }^{20}$ J.C. van't Spijker, P. Dorenbos, C.W.E. van Eijk, K. Krämer, and H.U. Güdel, J. Lumin. 85, 1 (1999).

${ }^{21}$ E.V.D. van Loef, P. Dorenbos, C.W.E. van Eijk, K.W. Krämer, and H.U. Güdel, Nucl. Instrum. Methods Phys. Res. A 486, 254 (2002).

${ }^{22}$ J. Andriessen, O.T. Antonyak, P. Dorenbos, P.A. Rodnyi, G.B. Stryganyuk, C.W.E. van Eijk, and A.S. Voloshinovskii, Opt. Commun. 178, 355 (2000).

${ }^{23}$ K. Kan'no, K. Tanaka, and T. Hayashi, Rev. Solid State Sci. 4, 383 (1990).

${ }^{24}$ K.S. Song and R.T. Williams, in Self-Trapped Excitons, edited by M. Cardona, Springer Series on Solid-State Sciences Vol. 105 (Springer-Verlag, New York, 1993).

${ }^{25} \mathrm{C}$. Görller-Walrand and K. Binnemans, in Handbook on the Physics and Chemistry of Rare Earths, edited by K. A. Gschneidner, Jr. and L. Eyring (Elsevier Science B.V., Amsterdam, 1996), Vol. 23, Chap. 155.

${ }^{26}$ M.N. Kabler and D.A. Patterson, Phys. Rev. Lett. 19, 652 (1967).

${ }^{27}$ L.F. Chen, K.S. Song, and C.H. Leung, Nucl. Instrum. Methods Phys. Res. B 46, 216 (1990).

${ }^{28}$ K. Tanimura and N. Itoh, J. Phys. Chem. 42, 901 (1981).

${ }^{29}$ G. Ascarelli and R.H. Sturen, Phys. Rev. B 11, 4045 (1975).

${ }^{30}$ T. Lida and R. Monnier, Phys. Status Solidi B 74, 91 (1976).

${ }^{31}$ R. Monnier, K.S. Song, and A.M. Stoneham, J. Phys. C 10, 4441 (1979).

${ }^{32}$ J.A. Hernandez, F.J. Lopez, H.S. Murrieta, and J.O. Rubio, J. Phys. Soc. Jpn. 50, 225 (1981).

${ }^{33}$ M.G. Aguilar, J.O. Rubio, F.J. Lopez, J. Garcia-Sole, and H. Murrieta, Solid State Commun. 44, 141 (1982). 